\title{
KEBUTUHAN TRAKTOR DALAM PERSIAPAN LAHAN SECARA MEKANIS PADA BUDIDAYA TEMBAKAU DI SUMATERA UTARA
}

Taufik Rizaldi

Program Studi Keteknikan Pertanian USU Medan 20155

Corresponding author : taufik.rizaldi@usu.ac.id

\begin{abstract}
ABSTRAK
Tujuan penggunaan tenaga traktor dalam persiapan lahan tembakau adalah untuk meningkatkan produksi dengan meningkatkan luas tanamnya. Produksi tembakau Sumatera Utara masih belum dapat memenuhi kebutuhan lokal namun produktivitasnya sebesar $1105.75 \mathrm{~kg} / \mathrm{Ha}$ melebihi produktivitas nasional sebesar $848 \mathrm{~kg} / \mathrm{Ha}$. Usaha untuk meningkatkan produksi sudah dilakukan dengan meningkatnya luas tanam Sumatera Utara sebesar 1305 Ha. Peningkatan luas tanam ini harus didukung dengan penggunaan traktor dalam persiapan tanahnya agar jadwal tanam yang direncanakan dapat terpenuhi. Jumlah traktor yang harus disediakan oleh Sumatera Utara untuk komoditi tembakau ini sebanyak 38 unit sedangkan bahan bakar yang diperlukan sebanyak 28215 liter.
\end{abstract}

Kata kunci: traktor, tembakau, produksi, produktivitas, bahan bakar

PENDAHULUAN

Tembakau dan Industri Hasil Tembakau (IHT) di indonesia memiliki peranan strategis dalam perekonomian nasional dan regional karena perannya sebagai sumber pendapatan negara, dan pendapatan petani serta penyedia lapangan kerja di pedesaan dan perkotaan. Pada tahun 2009 penerimaan cukai sebesar Rp. 55,4 triliyun, tahun 2010 sebesar Rp. 63,3 triluin, tahun 2011 sebesar Rp. 66,01 triliyun, tahun 2012 sebesar Rp. 95 trilyun, tahun 2013 sebesar Rp. 104 trilyun dan tahun 2014 sebesar Rp. 116,28 trilyun.

Perkembangan areal dan produksi tembakau berkorelasi dengan perkembangan produksi rokok. Areal dan produksi tembakau secara nasional pada tahun 2010 seluas $211.890 \mathrm{Ha}$, produksi 135.925 ton; tahun 2011 seluas 230.756 ton, produksi 218.556 ton; tahun 2012 seluas $270.015 \mathrm{Ha}$, 265.772 ton; tahun 2013 seluas $270.972 \mathrm{Ha}$, 174.030 ton dan tahun 2014 seluas 206.303 ha dengan produksi 222.288 ton.
Sasaran nasional dari kegiatan pengembangan tembakau adalah meningkatkan produksi dan produktivitas tanaman tembakau agar memenuhi standar dan kualitas yang dibutuhkan pabrikan. (Dirjen Perkebunan Kementerian Pertanian, 2015)

\section{KONDISI LUAS TANAM DAN PRODUKSI TEMBAKAU DI SUMATERA UTARA SAAT INI}

Daerah Sumatera Utara yang menjadi pusat pengembangan budidaya tanaman tembakau terdapat di Humbahas, Tapanuli Utara, Dairi, Simalungun, dan Tanah Karo. Jenis tembakau yang ditanam juga berbeda-beda. Daerah Humbahas, Tapanuli Utara, Dairi, dan Simalungun, jenis tembakau yang diproduksi adalah tembakau jenis white barle, sementara Tanah Karo jenis tembakau virginia. Kondisi luas lahan dan produksi tembakau di Sumatera Utara dalam buku Sumatera Utara dalam Angka (2014) dapat di lihat pada Tabel 1 berikut. 


$\begin{array}{lr}\text { Jurnal Pertanian Tropik } & \text { ISSN Online No : 2356-4725 } \\ \text { Edisi Khusus.Semnas Tembakau. } & \text { Vol.3, No.3. Desember 2016. (25) : 230- } 234\end{array}$

Tabel 1. Luas Tanaman dan Produksi Tembakau Tanaman Perkebunan Rakyat menurut Kabupaten 2014

\begin{tabular}{|c|c|c|c|c|c|}
\hline & \multirow{2}{*}{ Kabupaten } & \multicolumn{3}{|c|}{ Luas Tanam (Ha) } & \multirow{2}{*}{ Produksi (Ton) } \\
\hline & & Tanam & Panen & Jumlah & \\
\hline 1 & Nias & - & - & - & - \\
\hline 2 & Mandailing Natal & 28 & 28 & 28 & 38 \\
\hline 3 & Tapanuli Selatan & - & - & - & - \\
\hline 4 & Tapanuli Tengah & - & - & - & - \\
\hline 5 & Tapanuli Utara & 514 & 492 & 514 & 648 \\
\hline 6 & Toba Samosir & - & - & - & - \\
\hline 7 & Labuhan Batu & - & - & - & - \\
\hline 8 & Asahan & - & - & - & - \\
\hline 9 & Simalungun & 200 & 180 & 200 & 194 \\
\hline 10 & Dairi & 113 & 100 & 113 & 121 \\
\hline 11 & Karo & 198 & 195 & 198 & 223 \\
\hline 12 & Deli Serdang & - & - & - & - \\
\hline 13 & Langkat & - & - & - & - \\
\hline 14 & Nias Selatan & - & - & - & - \\
\hline 15 & Humbang Hasundutan & 222 & 180 & 222 & 201 \\
\hline 16 & Pakpak Bharat & 30 & 27 & 30 & 18 \\
\hline 17 & Samosir & - & - & - & - \\
\hline 18 & Serdang Bedagai & - & - & - & - \\
\hline 19 & Batu Bara & - & - & - & - \\
\hline 20 & Padang Lawas Utara & - & - & - & - \\
\hline 21 & Padang Lawas & - & - & - & - \\
\hline 22 & Labuan Batu Selatan & - & - & - & - \\
\hline 23 & Labuhan Batu Utara & - & - & - & - \\
\hline 24 & Nias Utara & - & - & - & - \\
\hline 25 & Nias Barat & - & - & - & - \\
\hline 26 & Gunung Sitoli & - & - & - & - \\
\hline & Total & 1305 & 1202 & 1305 & 1443 \\
\hline
\end{tabular}

Produksi yang dihasilkan petani tembakau masih belum mampu untuk memenuhi kebutuhan lokal sehingga masih membutuhkan pasokan dari luar khususnya daerah Jawa. Petani umumnya enggan memilih komoditi tembakau untuk dikembangkan. Mereka yang masih memilih komoditi tembakau umumnya keturunan petani tembakau dari generasi sebelumnya.
Investor juga kurang tertarik yang membuat pengelolaannya masih mandiri oleh masyarakat.

Berbeda dengan ekspansi sawit dan karet yang berkembang pesat karena campur tangan swasta. Sehingga Sumatera Utara masih belum mampu menyamai produksi tembakau seperti yang dihasilkan oleh Jawa Timur atau kawasan Jawa lainnya. Selain 
itu, jeda tanam (dibra) delapan tahun membuat komoditi ini kurang diminati oleh petani. Hal ini berakibat pada keberlangsungan usaha tani tembakau menjadi terkendala dikarenakan petani tidak dapat menanam tembakau kembali dilahannya dan harus mengalihkan ke komoditas lain.
Namun demikian, SumateraUtara dalam usaha untuk meningkatkan produksi tembakau sudah melakukan peningkatan luas tanam pada tahun 2014 menjadi 1305 Ha. Peningkatan luas tanam dalam buku Sumatera Utara dalam Angka (2014) dapat dilihat pada Tabel 2 berikut.

Tabel 2. Peningkatan luas tanam dan produksi tembakau Sumatera Utara

\begin{tabular}{cccccc}
\hline Tahun & $\begin{array}{c}\text { Luas Tanam } \\
(\mathrm{Ha})\end{array}$ & $\begin{array}{c}\text { Luas Panen } \\
(\mathrm{Ha})\end{array}$ & $\begin{array}{c}\text { Jumlah } \\
(\mathrm{Ha})\end{array}$ & $\begin{array}{c}\text { Produksi } \\
(\text { Ton })\end{array}$ & $\begin{array}{c}\text { Produktivitas } \\
(\mathrm{kg} / \mathrm{Ha})\end{array}$ \\
\hline 2011 & 512.7 & 439.7 & 512.7 & 374.66 & 730.76 \\
2012 & 645.6 & 584 & 645.6 & 496.88 & 769.64 \\
2013 & 639 & 530 & 639 & 481 & 752.74 \\
2014 & 1305 & 1202 & 1305 & 1443 & 1105.75 \\
\hline
\end{tabular}

Dari Tabel di atas dapat dilihat bahwa produktivitas tembakau Sumatera Utara sudah mengalami peningkatan. Hal ini dapat dilihat bahwa produktivitas tembakau pada tahun 2014 mencapai $1105.75 \mathrm{~kg} / \mathrm{Ha}$. Produktivitas yang dihasilkan lebih tinggi dari produktivitas tembakau nasional yaitu 848 kg/Ha (Dirjen Perkebunan, 2014).

\section{Persiapan tanah untuk tembakau jenis white barley}

Pembuatan bedengan diawali dengan pembabatan jerami sampai pangkal batang, kemudian dibuat got keliling dengan ukuran $40 \mathrm{~cm} \mathrm{x} 40 \mathrm{~cm}$. Selanjutnya dilakukan pembajakan I pada 25 hari sebelum penyebaran benih. Pembajakan I ini bertujuan agar kondisi tanah agak kering. Pada 14 hari sebelum penyebaran benih dilakukan pembajakan II yang bertujuan untuk menggemburkan tanah sampai besar butirannya diperkirakan sebesar biji jagung dan meratakannya. Setelah pembajakan II selanjutnya dilakukan pembentukan bedengan menggunakan cangkul dengan ukuran panjang $10 \mathrm{~m}$, lebar atas/permukaan $1 \mathrm{~m}$ dan lebar bawah bedengan $1.3 \mathrm{~m}$. Jarak antar bedengan $0.4 \mathrm{~m}$ dan tinggi bedengan 0.3-0.35 m. Pembentukan bedengan dilakukan 10 hari sebelum penyebaran benih (http://dokumen.tips/documents/budidayabarley.html)

\section{Persiapan tanah untuk tembakau jenis virginia}

Pengerjaan lahan dimulai dengan membersihkan sisa-sisa tanaman seperti rumput-rumputan, tunggak dan lain-lain, kemudian dicangkul dengan kedalaman 20 $\mathrm{cm}$ atau lebih. Sisa-sisa tanaman jangan ditimbun karena akan menjadi sarang rayap atau mendorong berkembangnya bibit-bibit penyakit. Jika masih banyak bongkahan tanah yang besar perlu dipecah ulang, sehingga ukuran tanah tinggal $2-3 \mathrm{~cm}$ atau kurang. Jika bongkahan tanah terlalu kecil atau terlalu lembut, tanah akan mudah mampat saat disiram air dan aerasi kedalam tanah kurang baik.

Selanjutnya ditetapkan ukuran bedengan $1,2 \mathrm{~m}$ x $10 \mathrm{~m}$ dan jarak antar guludan $50 \mathrm{~cm}$ dengan cara menaikkan tanah dari bagian calon selokan. Gunakan bantuan patok dan tali untuk memisahkan 
antar bedengan. Setiap 20 bedengan harus dibuatkan saluran atau got drainase untuk membuang air hujan atau air sisa pengairan. Ukuran bedengan $1,2 \mathrm{~m} \quad \mathrm{x} \quad 10 \mathrm{~m}$, memudahkan pengelolaan bedengan terutama pengawasan yang harus dilakukan intensif

(http://disbun.jatimprov.go.id/pustaka/phoca download/Budidaya\%20Tembakau\%20Virg inia.pdf)

\section{PENERAPAN MEKANISASI DALAM PERSIAPAN LAHAN UNTUK PENANAMAN TEMBAKAU}

Pada dasarnya pengolahan tanah untuk persiapan lahan yang dilakukan adalah dua kali pembajakan. Pembajakan pertama, tanah dipotong kemudian diangkat terus dibalik agar sisa-sisa tanaman yang ada dipermukaan tanah dapat terbenam di dalam tanah. Kedalaman pemotongan dan pembalikan umumnya di atas $20 \mathrm{~cm}$. Pada umumnya hasil pengolahan tanah masih berupa bongkah-bongkah tanah yang cukup besar, karena pada tahap pengolahan tanah ini penggemburan tanah belum dapat dilakukan dengan efektif. Pembajakan kedua, bongkah-bongkah tanah dan sisa-sisa tanaman yang telah terpotong pada pembajakan tanah pertama akan dibalik dan dihancurkan menjadi lebih halus tapi tidak terlalu halus dan sekaligus mencampurnya dengan tanah. Kedalaman pembajakan kedua umumnya dibawah $20 \mathrm{~cm}$ yang tujuannya adalah agar aerasi tanah lebih baik dan akar tanaman dapat mudah menembus tanah.

Pembajakan tanah pertama dan pembajakan tanah kedua sebaiknya dilakukan secara mekanis dengan menggunakan tenaga traktor. Keuntungan penggunaan tenaga mekanis adalah tenaga yang dihasilkan besar; ketahanannya baik, mampu bekerja 24 jam secara terus menerus; setiap saat dapat digunakan asal bahan bakar atau sumber panas tersedia dan dapat digunakan sebagai sumber tenaga alat mesin stationer atau mesin bergerak (Rizaldi, 2006).

Menurut Sakai, dkk (1998) bahwa kecepatan maju traktor untuk pembajakan berkisar antara 70-120 cm/det dengan ukuran lebar pembajakan $30 \mathrm{~cm}$. Berdasarkan ketentuan ini, maka kapasitas kerja teoritis traktor untuk pembajakan dapat ditentukan dengan asumsi kecepatan kerja traktor $95 \mathrm{~cm} /$ det dan lebar kerja bajak 30 $\mathrm{cm}$ yaitu sebesar $0.1026 \mathrm{Ha} / \mathrm{jam}$ atau 9.75 jam/Ha. Sehingga kapasitas kerja traktor sampai siap tanam menjadi $0.0513 \mathrm{Ha} / \mathrm{jam}$ atau 19.5 Jam/Ha.

Endang (2000), yang menyatakan bahwa jam operasi traktor roda dua adalah 600-750 jam/tahun (digunakan 750 jam/tahun), konsumsi energi rata-rata adalah 1,1 liter/jam. Jika diasumsikan kapasitas kerja traktor sama di setiap daerah penghasil tembakau di Sumatera Utara, maka dapat ditentukan kebutuhan traktor dan bahan bakarnya seperti yang disajikan pada Tabel 3 berikut. 
Tabel 3. Kebutuhan traktor dan bahan bakar

\begin{tabular}{llccc}
\hline Kabupaten & $\begin{array}{c}\text { Luas Tanam } \\
(\mathrm{Ha})\end{array}$ & $\begin{array}{c}\text { Kebutuhan Traktor } \\
\text { (unit) }\end{array}$ & $\begin{array}{c}\text { Kebutuhan Bahan Bakar } \\
\text { (liter/tahun) }\end{array}$ \\
\hline 1 & Mandailing Natal & 28 & 1 & 742.5 \\
2 & Tapanuli Utara & 514 & 15 & 11137.5 \\
3 & Simalungun & 200 & 6 & 4455 \\
4 & Dairi & 113 & 3 & 2227.5 \\
5 & Karo & 198 & 6 & 4455 \\
6 & Humbang Hasundutan & 222 & 6 & 4455 \\
7 & Pakpak Bharat & 30 & 1 & 742.5 \\
\hline Total & 1305 & 38 & 28215 \\
\hline
\end{tabular}

Dari Tabel 3 di atas menunjukkan bahwa jumlah traktor minimal yang harus tersedia di Sumatera Utara dalam perkebunan tembakau yang diusahakan oleh rakyat sebanyak 38 unit. Kabupaten Tapanuli Utara dengan luas tanam terbesar yaitu 514 ha harus menyediakan traktor sebanyak 15 unit dan bahan bakar 11137.5 liter.

\section{SIMPULAN}

Produksi tembakau Sumatera Utara belum dapat memenuhi kebutuhan lokal dan masih mendapat pasokan dari Jawa. Produktivitas tembakau Sumatera Utara melebihi produktivitas tembakau nasional. Untuk memenuhi kebutuhan tembakau, Sumatera Utara harus meningkatkan luas tanam

Persiapan tanah untuk tanaman tembakau sangat membutuhkan tenaga mekanis dari traktor

Sumatera Utara dengan luas tanam tembakau 1305 Ha membutuhkan 38 unit traktor dengan bahan bakar yang harus disediakan 28215 liter.

\section{DAFTAR PUSTAKA}

Direktorat Jendral Perkebunan Kementerian Pertanian, 2014. Statistik
Perkebuanan Indonesia 2013-2015. http://ditjenbun.pertanian.go.id/tinym cpuk/gambar/file/statistik/2015/TEM

BAKAU\%202013\%20-2015.pdf

Direktorat Jendral Perkebunan Kementerian

Pertanian, 2015. Peningkatan

Produksi dan Produktivitas Tanaman

Semusim.

http://ditjenbun.pertanian.go.id/tinym cpuk/gambar/file/pedumteknis/TANSIMPEDUMTEK\%20PENGEMBANGA \%20TANAMAN\%20TEMBAKAU\% 20(APBN-P\%202015).pdf.

Endang,S., 2005. Analisis Kebutuhan Energi pada Sektor Pertanian di Provinsi Gorontalo.http://www.geocities.com/ markalbptp/publish/grtalo/grsuar.pdf.

Rizaldi, T., 2006. Mesin Peralatan. Universitas Sumatera Utara, Medan.

Sakai J, Sitompul RG, Sembiring EN, Setiawan RPA, Suastawa IN dan Mandang T. 1998. Traktor 2-Roda. Laboraorium Alat dan Mesin Budidaya Pertanian, Jurusan Teknik Pertanian. Bogor (ID): Intitut Pertanian Bogor.

Sumatera Utara Dalam Angka, 2015. BPS Sumatera Utara, Medan 